\title{
AS CONCEPÇÕES DE ADOLESCENTE E AS METÁFORAS “IOIÔ”, "CANGURU” E “NEM NEM" COMO PROCESSOS SOCIAIS
}

\author{
J. A. G. STÊNICO', J. M. ADAM' \\ Universidade Estadual Paulista "Júlio de Mesquita Filho" - UNESP Campus Rio Claro \\ josellaine@yahoo.com.br' \\ Submetido 09/02/2016 - Aceito 25/02/2018 \\ DOI: $10.15628 /$ holos.2018.4101
}

\section{RESUMO}

Este artigo tem como objetivo refletir e debater criticamente os meandros relacionados à juventude brasileira, apresentando os desafios e limites desse segmento em um tempo de constantes mudanças. Trata-se de uma pesquisa qualitativa, utilizando como principais métodos de coleta de dados a pesquisa bibliográfica e o levantamento de variáveis estatísticas junto a grandes bases nacionais oficiais. Entre os principais resultados obtidos, pode-se destacar que o conceito de adolescente está relacionado a uma multiplicidade de temas que vão desde a visão naturalista do adolescente até conceituá-lo como um sujeito histórico e social. Além disso, os títulos denominados "ioiô", "canguru" e "nem nem" foram analisados enquanto processos sociais que atuam como instâncias simbólicas de reprodução social, refletindo diretamente nos conflitos vividos pelos jovens brasileiro.

PALAVRAS-CHAVE: Adolescente, Jovem, Processo Social.

\section{THE TEENAGER CONCEPTIONS AND THE METAPHORS “YO-YO”, “KANGAROO” AND “NO NO” AS SOCIAL PROCESSES}

\begin{abstract}
This paper aims to reflect and critically discuss the meanders related to Brazilian youth, presenting the challenges and limits of this segment in a time of constant change. This is a qualitative research, using as main methods of data collection the bibliographic research and the survey of statistical variables from large official national databases. Among the main results obtained, it can be noted that the concept of the
\end{abstract}

teenager is related to a variety of topics ranging from the teen's naturalistic view to conceptualize it as a historical and social subject the survey of statistical variables from large official national databases. Furthermore, the titles called "yo-yo", "kangaroo" and "no no" were analyzed as social processes that act as symbolic instances of social reproduction, reflecting directly in the conflicts experienced by Brazilian youth.

KEYWORDS: Teenager, Young, Social Process. 


\section{INTRODUÇÃO}

As transformações tecnológicas e a crescente globalização da economia, sem dúvida, são ímpares na dimensão que alcançam e velocidades que ocorrem, cada vez mais, tornam-se propulsoras, direta ou indiretamente, das principais mudanças vivenciadas pela sociedade capitalista, trazendo impactos e atingindo a vida das pessoas, sobretudo os adolescentes e jovens, sendo afetados nos seus modos de vida, na relação que estabelecem com o trabalho, a educação e a família, nos projetos de vida e nas formas de socialização.

De acordo com Hobsbawm (1995), a partir da década de 1950 nos Estados Unidos houve um momento expressivo de ascensão do jovem, principalmente, entre as classes média e alta e, desde então, a cultura juvenil se tornou dominante nas economias de mercado desenvolvido.

$\mathrm{Na}$ sociedade contemporânea muitas são as percepções sobre a juventude, oscilando entre a proposição de uma parcela significativa do mercado de consumo, assim como representações contraditórias sobre a noção do ser jovem, esse por último, em geral, tendem a rotular e prejulgar negativamente essa parcela da população, considerando-os revoltados, violentos, drogados, inconsequentes e entre outros.

Nessa perspectiva, embora os jovens possuam uma estreita relação com a cultura digital e tecnológica de nosso tempo, o que se nota é uma parcela populacional muito vulnerável, sujeitos à exclusão social devido a um conjunto de desequilíbrios provenientes do mercado, faltando-lhes perspectivas para o futuro.

Em razão dessa problemática, a discussão empreendida neste estudo tem como finalidade apresentar a multiplicidade de conceitos e definições relacionados à adolescência, assim como abordar o desafio de ser jovem em um tempo de mudanças no contexto da sociedade brasileira.

Em específico, o propósito deste artigo é analisar a produção teórica dos campos da Psicologia, da Educação e da abordagem sócio-histórica sobre a categoria adolescente. Além disso, busca-se apontar as relações existentes entre esta categoria e as questões da contemporaneidade, pontuando os fenômenos mais recorrentes entre os jovens brasileiros por meio de metáforas denominadas Geração "Ioiô", "Canguru" e "Nem Nem".

Vale ressaltar que no Brasil os adolescentes e os jovens são parametrizados por faixa etária. O Estatuto da Criança e do Adolescente (BRASIL, 1990) estabelece que o adolescente é aquele indivíduo que possui idade entre 12 e 18 anos incompletos. Já o termo "jovem" é designado para a população entre 15 a 24 anos de idade, de acordo com a Organização das Nações Unidas (ONU, 2005).

Considerando esses pressupostos, o texto foi organizado da seguinte maneira: Em um primeiro momento, foram apresentadas as definições e respectivas análises em torno da categoria adolescente sob as abordagens da Educação, da Psicologia e da Sociologia.

Em seguida, a discussão avança para o segmento juvenil, seguindo a definição de jovem de acordo com tendência internacional (15 a 24 anos), analisando, sobretudo, os conflitos da vida juvenil brasileira a partir das metáforas intituladas "loiô", "Canguru" e "Nem Nem" não como 
simples "gerações", mas como processos sociais que impactam diretamente nas condições da juventude na sociedade contemporânea.

\section{METODOLOGIA}

Para cumprir com os objetivos propostos, este estudo apresenta uma sequência de reflexões e análises a partir de uma pesquisa bibliográfica, sendo o conceito de adolescente tomado como referência básica para a análise, privilegiando uma visão crítica nas discussões. No processo de construção da pesquisa foram agregadas análises complementares que possibilitaram ampliar a discussão em torno da categoria adolescente.

Nesse sentido, pesquisas de cunho qualitativo podem, sem dúvida, contribuir no avanço dessa compreensão, haja vista que este tipo de abordagem permite alcançar a realidade na sua totalidade, possibilitando conhecer as interações que emergem de seu contexto (MACHADO, 2007).

Outra metodologia empregada neste estudo foi o levantamento de variáveis junto a grandes bases nacionais oficiais, especialmente, Instituto Brasileiro de Geografia e Estatística (IBGE, 2012), Pesquisa Nacional por Amostra de Domicílios (PNAD, 2011) e Instituto de Pesquisa Econômica Aplicada (IPEA, 2013) que jogam uma luz importante sobre os números da educação e são uma referência fundamental para o pleno entendimento da condição juvenil do País.

Embora a utilização de dados estatísticos neste estudo seja evidente e necessário, ainda assim, a investigação permanece com características qualitativas, pois Minayo (2001) explica que apesar das pesquisas quali quantitativa possuírem cada qual suas especificidades, as mesmas não se opõem, ao contrário, ambas interagem dinamicamente.

Desse modo, no decorrer da construção desta pesquisa nada impediu a utilização de dados estatísticos e variáveis numéricas, pois os mesmos permitiram captar indicadores de educação e de mercado de trabalho para a compreensão da condição juvenil na sociedade brasileira.

Vale ressaltar que os estudos mais recentes sobre o jovem e o adolescente nos mostram uma compreensão muito significativa da transformação sociedade, que tem como fator relevante o poder de criticidade na coletividade, destacando a educação como princípio que propicia a integração social entre os sujeitos, condição favorável às lutas e mobilizações.

\section{DEFINIÇÕES, REFLEXÕES E ANÁLISES DA CATEGORIA ADOLESCENTE}

Na literatura acadêmica há diversas definições para o que é ser adolescente. A falta de consenso conceitual é marcante entre os campos da Psicologia, da Sociologia e da Educação, isso indica, portanto, que não é possível encontrar uma forma efetiva ou um sentido exclusivo para definir a adolescência.

Assim, sem pretensão de se conceber um único conceito como certo, a análise aqui apresentada aborda, inicialmente, a definição de adolescência para o campo da Psicologia, seguida das abordagens sócio-histórica e educacional. 
Souza (2004) explica que na sociedade pré-industrial, a infância não estava separada do mundo adulto. Foi apenas em Emílio de Rousseau que surgiu uma concepção mais moderna, considerando a adolescência como o segundo nascimento. Essa ideia foi consolidada no século XIX, agregando-se novas características: a de uma fase turbulenta, caracterizada pelo excesso de paixão irracional que deveria ser vigiado e enclausurado. Desse modo, sob a influência da Psicologia, o século XX marca a adolescência como um processo de transição para o mundo adulto.

Mas foi Granville Stanley Hall, psicólogo e educador americano, que identificou no início do século XX que a adolescência é uma etapa marcada por tormentos e conturbações vinculadas à emergência da sexualidade, situando a adolescência como um processo na teoria evolutiva.

Em seguida, Erik Homburguer Erikson, psicólogo alemão, institucionalizou a adolescência como uma fase especial no processo de desenvolvimento, considerando esse momento como um período de transição entre a infância e a idade adulta.

As teorias desenvolvidas por esses estudiosos fizeram com que a concepção naturalista do adolescente tomasse forma e, em seguida, fosse amplamente compartilhada pelo campo da Psicologia. No Brasil, Arminda Aberastury e Maurício Knobel são referências no estudo da adolescência sob a ótica psicanalítica. Esses estudiosos apontam a adolescência como um momento difícil e doloroso marcado por contradições e crises (OZELLA, 2002).

Kehl (2004) ressalta que em todas as culturas a puberdade é marcada pela passagem da infância para a vida adulta. Trata-se de um período dilatado de espera que é vivido por aqueles que não são crianças, mas que ainda não se incorporaram à vida adulta, portanto, uma fase demarcada pela falta de maturidade intelectual e emocional.

Desse modo, portanto, as teorias desenvolvidas pela Psicologia tratam a questão da adolescência como uma fase natural do desenvolvimento humano, assim como um período intermediário entre a infância e a vida adulta, marcado, sobretudo, por comportamentos próprios dessa fase, especialmente: rebeldia, insatisfações e transformações corporais. Além disso, essa área de estudo considera a adolescência como um momento difícil e problemático da vida (BOCK, 2004).

Complementarmente, Coimbra et al. (2005) afirmam que os pressupostos científicos do século XX colocaram o adolescente como um objeto natural, com características e atributos bem demarcados. Nesse contexto, as práticas hegemônicas da Psicologia fortaleceram a propagação de um modelo baseado no princípio desenvolvimentista, onde o adolescente se torna um objeto construído de atributos psicológicos e biológicos, ou seja, uma figura que remete às questões de mudanças hormonais e corporais, bem como uma fase marcada por desinteresse, conflito, descontentamento, agressividade e melancolia.

A crise da adolescência pode ser explicada pela Psicanálise como um retorno do Complexo de Édipo, porém em proporções aumentadas, onde os desejos incestuosos se tornam ameaçadores em função da maturidade hormonal aliada às noções de liberdade (KEHL, 2004).

A ideia de naturalização da adolescência enquanto um momento de crise, de rebeldia, de transitoriedade, de turbulência, de tensão, de ambiguidade e de conflitos, foi internalizada pela sociedade que passou a considera-la como uma concepção universal, os adolescentes, por sua 
vez, reproduzem essas concepções instituídas socialmente, penetrando em sua subjetividade e constituindo-os (OZELLA e AGUIAR, 2008; BOCK, 2004).

A concepção desenvolvida pelo campo da Psicologia é bastante questionada pela abordagem sócio-histórica, Bock (2004), por exemplo, critica a visão naturalizante do adolescente por tratá-lo de modo abstrato, não favorecendo a valorização dos mesmos na sociedade. Além disso, a autora alerta para a superação desse conceito com vistas à construção de políticas públicas adequadas. Da mesma forma, Ozella e Aguiar (2008) afirmam que a Psicologia analisa o período da adolescência sob a forma naturalizante e a-histórica.

Desse modo, Bock (2004) propõe estudar a adolescência a partir da abordagem sóciohistórica pautada em Leontiev. Esse autor afirma que todas as aptidões e habilidades do homem são desenvolvidas com a própria ação humana sobre o mundo, assim, o resultado deste ato é cristalizado, incorporado ao objeto e deixado às gerações posteriores. Quando a geração seguinte atuar novamente sobre o mundo, uma vez mais, serão transformadas e, então, deixadas às gerações posteriores.

Coimbra et al. (2005) também propõem ampliar o conceito de adolescente com vistas a superar a concepção naturalizante, mas a partir das contribuições teóricas de Foucault, que considera-os como sujeitos que não possuem identidades fixas e impermeáveis, mas que são atravessados por uma multiplicidade de forças. Além disso, o desenvolvimento é entendido como uma construção permanente, onde a vida é um processo em que as características serão obtidas e, portanto, não pode ser reduzida a um modelo fixo.

A discussão em torno do adolescente a partir de sua realidade concreta também está no centro dos estudos de Ozella e Aguiar (2008). Os autores consideram que o homem se constrói a partir da relação dialética com a história e, portanto, trata-se de um ser único, singular e histórico.

Ao considerar esses pressupostos, a concepção de adolescente não é negada nem mesmo naturalizada, mas criada historicamente, constituindo-se com acepção na cultura e na linguagem, agregando-se fatos sociais que são atribuídos significados e que serão referências para formar os sujeitos (OZELLA e AGUIAR, 2008).

No que se referem ao desenvolvimento das características corporais, especialmente, os aspectos físicos e biológicos, os autores afirmam que esses elementos não interferem diretamente na subjetividade do sujeito, mas são significados pela sociedade.

A partir disso, Ozella e Aguiar (2008) têm conviçção que a totalidade social constitui os adolescentes, ao passo que a manutenção de concepções hegemônicas de adolescência, considerando-a como uma etapa fixa e estanque, apenas cumpre o papel de camuflar a realidade e as contradições sociais.

Nesse sentido, Takeuti (2012) alerta para a necessidade de se afastar a ideia de que o adolescente tem uma identidade única e pronta, ao contrário, são identidades que se constroem nos processos de enfrentamento, de oposição e de resistência que ocorrem no plano simbólico e material das relações sociais.

Do mesmo modo, Souza (2004) ressalta que considerar a adolescência como um momento de transição da infância para o adulto é ignorar as condições histórico-culturais, haja 
vista que a adolescência é uma categoria socialmente construída e, portanto, sujeito às mudanças ao longo do tempo.

Sendo assim, a autora propõe romper com a ideia de que os adolescentes são um grupo homogêneo com características comuns as idades e sugere avançar para a noção do adolescente como protagonista de um tempo de possibilidades, sob a ótica da diversidade.

No campo da educação, Charlot (2000) traz uma concepção bastante interessante, a noção do sujeito social. O sujeito enquanto "ser social" ocupa um lugar na sociedade e estabelece relações sociais.

O sujeito social é portador de uma história, é singular, é ativo, que consegue interpretar o mundo e dar-lhe sentido, ao mesmo tempo, age sobre o mundo e se produz nessa ação. Além disso, o sujeito social é aquele que "categoriza, organiza seu mundo, [...] dá sentido à sua experiência [...], o sujeito apreende o mundo e, com isso, se constrói e transforma a si próprio" (CHARLOT, 2000, p. 41).

Nesse sentido, o adolescente não pode ser considerado como algo estanque, mas como um sujeito social que está em processo de construção, onde na medida em que se constitui como ser social, integra-se como humano, desenvolvendo potencialidades da sua espécie. Além disso, Charlot (2000) explica que o aprender é algo intrínseco ao homem, é condição sine qua non na construção do sujeito:

Aprender para viver com os outros homens com quem o mundo é
compartilhado. Aprender para apropriar-se do mundo, de uma parte desse
mundo, e para participar da construção de um mundo pré-existente. Aprender
em uma história que é, ao mesmo tempo, profundamente minha, no que tem de
única, mas que me escapa por toda a parte. Nascer, aprender, é entrar em um
conjunto de relações e processos que constituem um sistema de sentido, onde
se diz quem eu sou, quem é o mundo, quem são os outros (CHARLOT, 2000, p.
53).

Sintetizando, observa-se que a concepção de adolescente para campo da Psicologia é uma etapa fixa definida por rebeldia e insatisfação, além disso, os elementos físicos e psicológicos marcam profundamente a transição da infância para vida adulta. Na abordagem sociológica e educacional, o adolescente é definido como ser histórico e social, respectivamente.

Nota-se, portanto, que a noção de adolescente é tomada por uma multiplicidade de enfoques e perspectivas, ora analisada de modo mais crítico, onde o adolescente é representante de diversas posturas e um sujeito histórico e social pronto para atuar sob a realidade que o circunda, ora a análise se pauta na visão naturalizante do adolescente, como uma fase do desenvolvimento humano, aceitando a condição de período de transição, atravessado por sucessivas crises.

Vale ressaltar que as discussões em torno do adolescente sob o campo da Psicologia, certamente, favoreceu que o homem comum assimilasse com mais facilidade o comportamento dos adolescentes por estar submerso em uma cultura que não permitisse confrontar com outra perspectiva, favorecendo que o sujeito não tenha outra concepção de modo espontâneo ou refletido, daí a noção do adolescente como uma etapa fixa no processo de desenvolvimento humano passa a ser considerada como uma definição universal. 
Os adolescentes, por sua vez, tomam essa definição como uma verdade real e absoluta que ao aceitá-la como tal, decide todo o sentido de sua existência, declarando que não existe história humana e tampouco algum significado histórico e social.

Em última análise, essas considerações a cerca das concepções de adolescente remonta a um totalitarismo no diálogo, onde não há outra definição a ser discutida e pensada, senão aquela que está institucionalizada, desse modo, conseguiu-se introduzir na sociedade uma espécie de consenso que vai ao encontro à expectativa social e esse sentido é provavelmente o que está profundamente fixado na mentalidade social.

\section{GERAÇÃO METAFÓRICA VERSUS PROCESSOS SOCIAIS}

Ao tomar a definição de jovem como uma construção histórica e social e que, portanto, cada época postula diferentes maneiras de ser jovem e, ainda, ao considerar que o jovem é produção de uma determinada sociedade, relacionada com as formas de ver os jovens, quais são as percepções que a sociedade contemporânea tem do jovem brasileiro?

Os estudos mais recentes do IBGE (2012) categorizam os jovens em, pelo menos, três gerações: "Ioiô", "Canguru" e "Nem Nem".

De acordo com Pais (2001), a Geração loiô é uma metáfora para ilustrar jovens nos processos de ida e vinda entre o sistema educativo e o mercado de trabalho, entre viver em casa própria ou na casa dos pais, ou ainda, a opção de ter uma vida de casado ou uma vida de solteiro.

Os jovens que integram a Geração loiô abandonam a escola, adquirem emprego e se casam, ou seja, deixam de ser jovens e passam a ser adultos, mas em seguida, tornam-se desempregados, divorciam, voltam a estudar e por não conseguirem assumir-se autonomamente, retornam a casa dos pais e novamente redescobrem a juventude. Esse processo de ir e vir, de avançar e retroceder simula os movimentos do brinquedo loiô de cair e subir, daí seu nome.

Nota-se, portanto, que os jovens que compõem a Geração loiô integram um modelo cultural que se manifesta na rapidez, traduzindo uma ideia de vida inconstante e instável. 0 jovem com uma nova mentalidade onde as mudanças constantes são consideradas como algo natural. Sobre isso, Baumann (2001) explica que a geração de jovens de hoje substitui uma antiga mentalidade por uma nova mentalidade:

[...] é a nova mentalidade de "curto prazo", que substituiu a de "longo prazo". Casamentos "até que a morte nos separe" estão decididamente fora de moda e se tornaram uma raridade: os parceiros não esperam mais viver muito tempo juntos. De acordo com o último cálculo, um jovem americano com nível médio de educação espera mudar de emprego 11 vezes durante sua vida de trabalho e o ritmo e frequência da mudança deverão continuar crescendo antes que a vida de trabalho dessa geração acabe (BAUMANN, 2001, p. 169).

No contexto da sociedade brasileira, um exemplo contundente dessa geração inconstante é a alta rotatividade de emprego recorrente entre os mais jovens. Dados do IPEA (2013) revelam que a contratação de jovens em 2000 estava na casa dos 4,6 milhões, já em 2010 o número subiu 
para 8,56 milhões, ou seja, um incremento de aproximadamente $85 \%$. Embora os dados sejam expressivos, o número de demissão na mesma época passou de 3,47 milhões para 6,75 milhões.

Outro dado interessante da PNAD de 2011 é que 51,1\% dos jovens com até 24 anos e $59,4 \%$ com idade entre 25 a 29 anos foram desligados de empresas, em seguida, $62,5 \%$ foram substituídos por outros jovens com a mesma qualificação.

Esses dados sinalizam que a substituição de mão de obra jovem não ocorre por conta da inadequação do perfil do empregado à vaga e que a mudança de emprego excessiva pode indicar uma imposição do mercado de trabalho.

De acordo com Martins (2002), a redução do número de empregados, deve-se, sobretudo, as transformações no próprio processo produtivo da empresa com a introdução de inovações tecnológicas e as alterações na organização do trabalho que exigem um novo tipo de trabalhador. Nesse sentido, as constantes mudanças no mercado de trabalho não garantem com segurança a sobrevivência do trabalhador.

Outro fenômeno recorrente entre os jovens é a chamada "Geração Canguru", essa titulação se refere àqueles jovens que prolongam o tempo de permanência na casa dos pais, tal como o mamífero marsupial Canguru que carrega seu filhote em uma bolsa para completar seu desenvolvimento, já que nascem imaturos.

De acordo com o IBGE (2012), houve um incremento entre o número de jovens com idades entre 25 e 34 anos que ainda moram com os pais. Em 2002 o percentual era de 20,5\%, já em 2012 esse número subiu para 24,3\%, ou seja, a população "canguru" cresceu no período de dez anos, entretanto, esse número é inferior com famílias que recebem até meio salário-mínimo, chegando apenas $6,6 \%$.

Em compensação, famílias com rendimentos entre dois a cinco salários-mínimos, essa porcentagem sobe para 15,5\%, enquanto que rendimentos superiores a cinco salários-mínimos, a taxa é de 14,7\%. Além disso, a taxa de ocupação dos jovens cangurus é de $91,4 \%$, enquanto que a média é de 93,7\%, em contrapartida, o percentual de estudos dos cangurus é quase um ano a mais, 10,8 anos, sendo a taxa mediana de 9,9 anos.

Agregam-se a esses dados, duas exigências que obrigam o jovem adulto a viver cada vez mais tempo na condição de dependente da família: o jovem como um consumidor em potencial e o jovem que precisa se qualificar profissionalmente para enfrentar o concorrido mercado de trabalho.

No que se refere à primeira exigência, Kehl (2004) explica que a juventude é uma fatia de mercado onde todos os capitalistas querem incluí-los, pois é um segmento que consome e consome muito. Esse quadro favorece uma cultura altamente hedonista, proporcionando a criação de uma imagem industrializada: um jovem consumidor que desfruta de todas as liberdades da vida adulta, mas que é poupado de quase todas as responsabilidades. Essa noção do jovem canguru passa a ser defendida pela publicidade, oferecendo para todas as classes sociais a identificação com essa imagem (KEHL, 2004).

Nesse sentido, Takeuti (2012) explica que um dos paradoxos que os jovens enfrentam nessa sociedade é a ideia exacerbada de que eles são sustentados por uma indústria cultural que os elegem como sendo a fatia privilegiada do mercado consumidor. As sociedades atuais pautam- 
se nas tecnologias de informação e comunicação que operam na subjetividade humana, controlando continuamente a vida, modulando os fluxos sociais e os desejos.

A noção de jovem consumidor é intensificada pelo sistema neoliberal onde o conceito de juventude se remete à lógica do capitalismo, Coimbra et al. (2005) analisam a concepção por essa ótica e a intitulam de "individualista e culpabilizante da subjetivação capitalística". Para os autores, o jovem é determinado pelo próprio indivíduo, ou seja, as qualidades, defeitos, méritos e fracasso são atribuídos como inerentes à sua natureza.

Isso implica que quanto mais os jovens se tornam alvos do mercado de consumo, sobretudo, os que pertencem a classes menos privilegiadas, menores são as chances de se tornar consumidor, como resultado é o aumento exponencial da violência, delinquência e uso de drogas, esses são os principais sintomas emergentes entre os jovens dos países industrializados, assim como, são os laços que compõe a sociedade de consumo (TAKEUTI, 2012; KEHL, 2004).

No que se refere à segunda exigência para a condição do jovem canguru é a justificativa de que se precisa qualificar profissionalmente para adquirir um posto de trabalho. Trata-se de um período de latência social, constituindo uma fase de afastamento do trabalho e o preparo para a vida adulta.

Bock (2004) afirma que com os avanços tecnológicos e a sofisticação do trabalho foi necessário aumentar o preparo técnico para ingressar no mercado de trabalho e, assim, retardar o desemprego. Desse modo, as novas tecnologias exigem, cada vez mais, investimento em capacitação profissional para quem procura se destacar e encontrar melhores oportunidades no mercado de trabalho.

Portanto, o preparo para as responsabilidades da vida adulta, a qualificação profissional, a busca de um emprego e a constituição de uma família tardiamente obrigam o jovem adulto a viver mais tempo na condição de dependente da família.

Desse modo, uma possível análise daqueles que compõe a Geração Canguru é que se trata de jovens que pertencem às classes média e alta, apresentando-se com, pelo menos, dois perfis:

O primeiro perfil, sob a perspectiva do comportamento do consumidor. O prolongamento da convivência familiar visa atender às necessidades, desejos e motivações dos jovens, pois ao viverem com os pais não têm despesas com moradia e contas diversas, destinando seus rendimentos ao consumo.

O segundo perpassa pela perspectiva da carreira profissional, onde os jovens dedicam-se aos estudos para atender às exigências do mercado de trabalho, explicitando uma possibilidade de investir na formação profissional para adquirir mais chances no competitivo mundo de trabalho, obrigando, desse modo, que o jovem seja dependente da família.

Seja qual for o perfil do jovem, o adiamento da separação da família é um reflexo do contexto social fortemente marcado por instabilidade e incerteza. A permanência na casa dos pais é um indicativo de que o jovem pode se preparar melhor para a competição acirrada do mercado de trabalho, sem dispor de renda monetária, pois há a dependência dos pais para sua sobrevivência e qualificação, sugerindo, desse modo, que os pais "carreguem" seus filhos por mais tempo, tal como um canguru que aguarda o pleno desenvolvimento de seu filho. 
Outro processo recente no mundo dos jovens é fenômeno intitulado "Geração Nem Nem", trata-se de outra metáfora associado aos jovens que nem trabalham e nem estudam. De acordo com dados do IBGE baseado na Pnad de 2012, quase um quinto dos jovens pertencem a geração "Nem Nem", ou seja, são 9,8 milhões de jovens com idade entre 15 a 29 anos, sendo a maioria formada por mulheres, chegando a $70,3 \%$.

Entre esse grupo de mulheres, 58,4\% declararam que tinham, pelo menos, um filho. Um ponto mais aterrador é a identificação de que jovens entre 15 a 24 anos sequer completaram o ensino fundamental.

Outro dado alarmante divulgado pelo IBGE (2012) é que apenas 38,6\% dos jovens "Nem Nem" concluíram o ensino médio, sendo a maior parte formada pelo grupo com idade entre $18 \mathrm{e}$ 24 anos, representando $43,2 \%$. Apenas 5,6\% possuíam ensino superior completo ou incompleto e $32,4 \%$ trata-se de jovens que não concluíram o ensino fundamental.

Desse modo, considerando os dados do IBGE e Pnad, uma possível explicação pelos quais os jovens se tornam um "Nem Nem", deve-se a uma relação bastante direta com a questão da maternidade, pois quase $60 \%$ mulheres na condição de Nem Nem possuíam um filho pelo menos, o que é um número muito expressivo.

A gravidez na adolescência pode ser um fator do abandono escolar e como consequência inevitável é um segmento com baixa qualificação profissional, competindo com outros jovens de maior escolaridade. O resultado não poderia ser outro, senão uma massa de jovens sem trabalho e sem estudos.

Takeuti (2012) explica que os jovens podem até dominar melhor as ferramentas tecnológicas, podem, ainda, até mais anos de estudos que seus pais, entretanto, eles estão cada vez mais excluídos dos processos de inclusão no mercado de trabalho. Outra parcela, nem sequer foram incluídos do processo de aquisição de competências, pois interrompem seus estudos para se lançar ao trabalho e se veem na iminência da marginalização, cada vez mais enveredando pelos caminhos da delinquência.

Isso implica que os jovens da geração "Nem Nem" passam por um processo de reclusão do mercado de trabalho e do acesso à educação, restando-lhes o trabalho informal, sem garantias. Essa discussão sinaliza outro debate: embora os jovens possuam possibilidades e escolhas múltiplas, nem sempre são possíveis, haja vista a escassez de empregos que os torna como um dos principais segmentos da população ativa mais fragilizada (SOUZA, 2004; MARTINS, 2002).

Diante da complexidade em torno do jovem, nota-se que a Geração "Canguru" atinge uma classe mais privilegiada, ao passo que a Geração "Nem Nem" está mais associada aos menos favorecidos, enquanto que a Geração "Ioiô" pode atingir ambas as classes sociais, porém alcançando de modo acentuado os mais afortunados. Um ponto em comum entre todas as gerações é a relação que estabelecem com a educação e o trabalho.

Contudo, apesar do uso das gerações metafóricas para compreender os jovens na sociedade contemporânea, essa produção apresenta uma lacuna: As "gerações" intituladas ioiô, canguru e nem nem, na verdade não são gerações, são processos sociais e culturais que estão impactando sobre as condições da juventude em seus caminhos de vida e trânsitos para idade adulta. 
Estes processos ao nível do sujeito e das estruturas sociais, especialmente, a influência da escolaridade, emprego, independência econômica, a independência residencial e maternidade/ paternidade são elementos clássicos e marcos dos caminhos da vida adulta dos jovens.

Santos (1999) afirma que os processos sociais se elegem como campos de relações de forças que privilegiam as práticas, assim, as representações sociais adquirem novos contornos e se disseminam por toda a sociedade. A constituição de novos processos sociais é resultado dos efeitos da globalização da sociedade e da economia contemporânea sobre as transformações da estrutura e do espaço social. Canclini (2005) assevera também que os processos sociais e culturais se produzem, circulam e consomem na história social, transformando o objeto através de usos e reapropriações sociais.

Desse modo, a utilização dos processos sociais intitulados ioiô, canguru e nem nem para representar a situação dos jovens brasileiros atuam como instâncias simbólicas da reprodução social desenvolvendo novos significados e refletindo diretamente os conflitos da vida juvenil frente aos ditames da sociedade contemporânea, regulando e justificando sua conduta e enquadrando-o em uma das "gerações".

Essa noção induz a pensar que o processo de mudança da sociedade é de responsabilidade dos jovens. Isso é bastante complexo, porque a própria organização da sociedade dentro da lógica capitalista se empenha em manter o jovem na cadeia de consumo.

Além disso, sob a lógica capitalista é preciso manter uma parcela significativa da população "precariamente incluída" (MARTINS, 2002) para que a parcela menor possa estar "plenamente incluída" e fazer uso dos bens econômicos, educacionais e culturais a disposição na sociedade.

Desse modo, o processo de "expulsão" da cadeia econômica faz parte desse sistema capitalista perverso, em relação ao quais, os jovens não podem ser responsabilizados pela mudança e tampouco esperar que eles próprios possam superar tais limites sem um projeto de sociedade realmente inclusivo.

\section{CONCLUSÃO}

O artigo permitiu compreender as diversas concepções de adolescente, sobretudo para as áreas da Psicologia, da Sociologia e da Educação. A primeira considera o adolescente como uma fase constituída de crises e transformações corporais, sendo, portanto, uma etapa fixa do princípio desenvolvimentista. Enquanto que a segunda, analisa o jovem sob a percepção da realidade concreta, construído ao longo da história humana e, finalmente, no campo educacional tomou-se a concepção de Charlot (2000), considerando o adolescente como sujeitos sociais.

Além disso, refletiu-se sobre os meandros da juventude brasileira, sob a perspectiva das Gerações "Ioiô", "Canguru" e "Nem Nem". Os dados apresentados, as respectivas reflexões e análises sugeriram o aumento da vulnerabilidade desse grupo social, surgindo o problema da exclusão social. O jovem está diante de um quadro de incertezas da obtenção da condição adulta, de sua emancipação e autonomia.

O discurso vigente parece estabelecer que o jovem deva se constituir a partir do trabalho e da educação. Bock (2002) afirma que vivemos uma crise onde a única saída existente é via 
educação, haja vista a qualificação é necessária para atender as demandas do capitalismo, mas não basta uma qualificação profissional, o jovem tem de ser polivalente e dominar todas as áreas para disputar um mercado altamente competitivo.

Nesse sentido, da educação tem se exigido seguir no ritmo ordenado pelo concorrido mercado de trabalho que busca constantemente por recursos humanos cada vez mais qualificados, flexíveis e polivalentes, em contraponto, o jovem precisa se adequar as questões, que atualmente se tornaram hegemônicas.

Nesse processo débil, apenas e tão somente, os mais "bem-educados" terão chance [ou alguma] no mercado globalizado, daí a exclusão social não é culpa do governo, mas sim do trabalhador que não se qualifica. Isso significa que uma educação que deveria ser para todos na prática é excludente.

Por isso é um desafio enorme aos adolescentes e jovens dentro desse cenário nebuloso ao qual se encontra a sociedade brasileira. Cotidianamente, os jovens se deparam com grandes impasses pela busca de seus direitos de trabalhar, de estudar, de realizar seus sonhos e projetos de vida.

De acordo com Souza (2004), essa insegurança acentua a indefinição dos jovens ao ingressarem ao mundo adulto. Takeuti (2012), por sua vez, ressalta que o modo de produção capitalista, os novos rumos econômicos e as inovações tecnológicas colocam desafios aos jovens, confrontando os processos de subjetivação.

Mas, em absoluto, os jovens não podem ser culpabilizados pelas escassas possibilidades de inserção, permanência e valorização do trabalho e da educação. Para que os jovens tornem-se atores protagonistas na sociedade em que vivem e agentes construtores de mudanças, é necessário, antes de tudo, de uma sociedade com um projeto real de inclusão desse segmento.

É certo que esta perspectiva impõe dificuldades e desafios, pois encontrará desafiando uma ordem estabelecida nesta sociedade que busca manter o homem não-emancipado e, portanto, qualquer tentativa de condução desta sociedade à emancipação encontrará resistências, porém um repensar das políticas educativas e dos saberes a serem trabalhados no cotidiano educacional é urgente e requer que os olhares daqueles que buscam a superação deste modelo de sociedade alienada, possibilitando, desse modo, aos jovens constituírem-se como atores sociais permitindo atuar e a intervir na própria realidade.

\section{REFERÊNCIAS}

Baumann, Z. (2001). Modernidade líquida. Rio de Janeiro, Zahar Editora.

Bock, A. M. B. (2004). A perspectiva sócio-histórica de Leontiev e a crítica à naturalização da formação do ser humano: a adolescência em questão. Cad. Cedes, Campinas. Vol. 24, n. 62, p. 26-43.

Bock, S. D. (2002). A inserção do jovem no mercado de trabalho. In: Abramo, H.W.; Freitas, M. V. de; Sposito, M. P. Juventude em Debate. São Paulo: Contez, 2a Edição, p. 11-40.

Brasil. Estatuto da criança e do adolescente (1990). Estatuto da criança e do adolescente: Lei n. 8.069, de 13 de julho de 1990, Lei n. 8.242, de 12 de outubro de 1991. - 3. ed. - Brasília : Câmara dos Deputados, Coordenação de Publicações. 
Canclini, N. G. (2005). Diferentes, desiguais e desconectados: mapas da interculturalidade. Rio de Janeiro: Ed. UFRJ.

Charlot, B. (2000). Da relação com o saber: elementos para uma teoria. Porto Alegre: Artemed.

Coimbra, C.; Bocco, F.; Nascimento, M. L. do. (2005). Subvertendo o conceito de adolescência. Arquivos Brasileiros de Psicologia. Vol. 57, n. 1, p. 02-11.

Hobsbawm, E. J. A era dos extremos: o breve século XX (1914-1991). 2a Edição, Tradução de Marcos Santarrita. São Paulo: Companhia das Letras, 1995.

Ibge. Instituto Brasileiro de Geografia e Estatística. (2012). Síntese de Indicadores Sociais. Disponível em: <http://www.ibge.gov.br/home/>

Ipea. Instituto de Pesquisa Econômica Aplicada. (2013). Emprego: Rotatividade de jovem deixa país menos competitivo. Disponível em: <http://www.ipea.gov.br/>

Kehl, M. R. (2004). A juventude como sintoma da cultura. In: Novaes, R.; Vannchi, P. (orgs). Juventude e Sociedade: trabalho, educação e participação. São Paulo: Editora Fundação Perseu Abramo, p. 89-114.

Machado, M. N. M. (2007). Entrevistas de pesquisa não-estruturadas e semi-estruturadas In: Administração, Metodologia, Organizações, Estratégia. Curitiba: Juruá Editora 2ª̣ed.

Martins, H. H. T. S. (2002). A Juventude no contexto da reestruturação produtiva. In: Abramo, H. W.; Freitas, M. V. de; Sposito, M. P. Juventude em Debate. São Paulo: Contez, 2a Edição.

Minayo, M. C. S. (2001). Pesquisa Social. Teoria, método e criatividade. 18 ed. Petrópolis: Vozes.

Onu. Organização das Nações Unidas (2005). World youth report 2005: young people today, and in 2015. United Nations publication, October.

Ozella, S. (2002). Adolescência: uma perspectiva critica. In: Contini, M. L. J.; Koller, S. H. Adolescência e psicologia: concepções, práticas e reflexões críticas. Rio de Janeiro. Conselho Federal de Psicologia, p. 16-24.

Ozella, S.; Aguiar, W. M. J. (2008). Desmistificando a concepção de adolescência. Cadernos de Pesquisa. Vol. 38, n. 133, p. 97-125.

Pais, J. M. (2001). Ganchos, tachos e biscates: jovens, trabalho e futuro. Porto: Âmbar.

Pnad. Pesquisa Nacional por Amostra de Domicílios. (2011) Microdados. Disponível em:<https://ww2.ibge.gov.br/home/estatistica/populacao/trabalhoerendimento/pnad201 1/default_sintese.shtm>

Santos, J. V. T. (1999). Novos processos sociais globais e violência. São Paulo Perspec. Vol. 13, n. 3, São Paulo, p. 18-23.

Souza, C. Z. G. (2004). Juventude e Contemporaneidade: possibilidades e limites. Última Década. Vol. 12, n. 20, p. 47-69.

Takeuti, N. M. (2012). Paradoxos societais e juventude contemporânea. Estudos de Psicologia, 17(3), p. 427-434. 